\title{
The Circular Economy and the Leading European Retailers: A Research Note
}

\author{
Peter Jones ${ }^{1 *}$, Daphne Comfort ${ }^{1}$ \\ ${ }^{1}$ University of Gloucestershire, Business School, Pallas Villa, Park Campus, Cheltenham, UNITED KINGDOM
}

*Corresponding Author: pjones@glos.ac.uk

Citation: Jones, P. and Comfort, D. (2018). The Circular Economy and the Leading European Retailers: A Research Note. European Journal of Sustainable Development Research, 2(2), 13. https://doi.org/10.20897/ ejosdr/82983

Published: March 7, 2018

\begin{abstract}
The concept of the circular economy is gaining momentum in political and business thinking about the transition to a more sustainable future. EuroCommerce and the European Retail Round Table, for example, have argued that leading retailers are keen to play a leading role in shaping the circular economy within Europe. This exploratory research note outlines the characteristic features of the concept of the circular economy, provides some illustrations of how Europe's leading retailers are publicly addressing circular economy approaches and offers some general reflections on the application of the concept within the retail sector of the economy. The findings reveal that almost $50 \%$ of the leading European retailers signalled a commitment to the circular economy and to the principles underpinning it and a number of them looked to evidence their commitment within their retail operations. That said the authors suggest that If Europe's leading retailers' public commitments to a more circular economy are to become a reality then they will not only need to effect a radical change in their current business models and that this will need to be accompanied by radical changes in consumers consumption behaviour. More contentiously, there must be concerns that the leading European retailers might effectively capture the concept of the circular economy to justify continuing economic growth.
\end{abstract}

Keywords: circular economy, European retailers, consumption behaviour, sustainable consumption

\section{INTRODUCTION}

The concept of the circular economy is gaining increasing momentum in political and business thinking about the transition to a more sustainable future. The European Commission (2015, webpage), for example, argued that the transition to a more circular economy, where the value of products, materials and resources is maintained in the economy for as long as possible, and the generation of waste is minimised, is an essential contribution to the European Union's efforts to develop a sustainable, low carbon, resource efficient and competitive economy.' The circular economy embraces all stages of the product life cycle from both the product design and the production process, through marketing and consumption to waste management, recycling and re-use. Accenture Strategy (2015, webpage), for example, suggested 'transitioning to the circular economy may be the biggest revolution and opportunity for how we organize production and consumption in our global economy' and that 'at its essence, the circular economy represents a new way of looking at the relationships between markets, customers and natural resources.' PricewaterhouseCoopers (2017, webpage) argued 'ultimately the circular economy is about rethinking everything, including business models themselves, so we can reduce consumption.

In many ways, large retailers, who are the active intermediaries between producers and consumers, have a potentially crucial role to play in moving towards a more sustainable economy and society. Indeed, EuroCommerce and the European Retail Round Table (2015a, p.1) claimed that 'Europe is leading the world in this shift', that 'retailers are a large contributor to the European Union economy' and as 'responsible economic operators' they 'are keen to take a front seat 
in shaping a circular economy in Europe.' In a similar vein, Adela Torres Calatayud, Environment Committee Chair of EuroCommerce and Environment Manager for Mercadona, the Spanish supermarket chain, suggested 'retailers have a key role to play in sharing the benefits of the circular economy as millions of European consumers buy their products in our stores every single day' (European Retail Round Table 2017, webpage). To date, little or no research on the introduction of the circular economy within the retail sector of the economy has been published in the academic literature. Although Wiese et al. (2015, p.298) drew up a framework for sustainability research in retailing, which was structured around 'sustainability products', 'sustainable processes' and 'motivating consumers', the concept of the circular economy was not mentioned. With these thoughts in mind, this exploratory research note outlines the characteristic features of the concept of the circular economy, provides some illustrations of how Europe's leading retailers are publicly addressing circular economy approaches and offers some general reflections on the application of the concept within the retail sector of the economy.

\section{THE CONCEPT OF THE CIRCULAR ECONOMY}

While Murray et al. (2015, p.10) suggested that the term circular economy has 'been linked with a range of meanings and associations by different authors' they argued that in its most basic form 'a circular economy can be loosely defined as one which balances economic development with environmental and resource protection.'The Ellen McArthur Foundation, which was established in 2010 with the aim of accelerating the transition to a circular economy, argued that 'a circular economy is restorative and regenerative by design, and aims to keep products, components, and materials at their highest utility and value at all times' and that 'the circular economy is a continuous, positive development cycle. It preserves and enhances natural capital, optimises resource yields, and minimises system risks by managing finite stocks and renewable flows' (Ellen McArthur Foundation 2017, webpage). In practice, circular economies are popularly seen to be built around a range of activities, which look to reduce the demand for raw material inputs and natural resources and to recover, recycle and re-use inputs and resources as an integral part of the production process. As such the concept of the circular economy is contrasted, by its proponents, with the traditional 'linear economy' which turns raw materials into waste in the production process and which is seen to lead to environmental pollution and the removal of natural capital from the environment.

Essentially the concept of the circular economy embraces all stages of the product life cycle from both the product design and the production process, through marketing and consumption to waste management, recycling and re-use. Within such an economy an initial focus on designing products that are more resource efficient throughout their life cycles can make products more durable, easier to repair and to recover constituent, and potentially still useful, materials from the products when their initial lifespan is over. As long as the majority of environmental costs are borne not by producers but more generally by a potentially wide range of stakeholders then there is limited incentive to introduce more innovative design thinking. The circular economy also demands greater efficiency in production processes and here the focus is on looking to reduce the environmental and social impact of production, for example, through more sustainable sourcing and the promotion of innovative industrial processes.

Consumers have a vital role to play if there is to be a transition to a more circular economy. In theory much will be expected of consumers, not least in that they need to be prepared to embrace what they may see as radical new buying behaviours and consumption practices. A number of factors are at work here, but price is widely seen to be an important factor in determining consumer buying behaviour. While there are deeper-rooted problems in looking to use regulatory frameworks to try to ensure that prices more adequately reflect environmental costs and social benefits there may be more, though currently limited, mileage in using incentives to achieve the same goal. Within a circular economy, waste management is no longer seen as a problem, but rather as an opportunity to return as much waste as possible back into productive use. The focus is on the prevention, reuse and recycling of waste materials rather than their disposal by landfill. Where waste cannot be prevented, reused or recycled then recovering its energy content is seen preferable to landfill and waste to energy solutions are also seen to be integral to the circular economy. More generally, the circular economic model also looks to investigate and promote new markets for waste materials.

A number of factors help to explain the pressure for the transition to a more circular economy. These factors include the continuing depletion of scarce natural resources, the supply problems associated with the increasingly volatile international political situation and the unpredictable events associated with climate change, and the potential price volatility associated with both these factors. At the same time, the continuing environmental degradation and natural resource depletion associated with the current dominant traditional (capitalist) business model, the increasing introduction of national and international statutory legislative regulation designed to reduce environmental problems, and investment in technological innovations which promote the more efficient use of natural resources are all important drivers for a circular economy. More generally, indications of the emergence of 
new strategic corporate thinking that recognises that the imperatives of business continuity will encourage the adoption of new and more resilient business models.

A variety of potential environmental gains, energy generating opportunities and business benefits are claimed for a transition to a circular economy. These benefits include substantially reduced carbon dioxide emissions, greater use of renewable sources of energy, reduced pollution levels, the production of energy from waste materials and increased growth and profitability. The World Economic Forum (2014, p.13) estimated that globally the circular economy is a 'trillion dollar opportunity with buge potential for innovation, job creation and economic growth.' Further McKinsey and Company (2015, webpage) argued that a circular economy 'would allow Europe to grow resource productivity by up to 3\% annually' and that it could generate a net economic benefit of 1.8 trillion Euros by 2030 . More specifically EY (2015, p.10) suggested that 'the circular economy helps to contain risks', for example, in managing raw material supply in competitive markets, and in providing opportunities to 'extend and strengthen customer relationships', 'tap into new markets', 'become more efficient' and 'yield extra income.'

\section{RETAILERS' COMMITMENTS TO THE CIRCULAR ECONOMY}

In March 2009 a number of European retailers in conjunction with EuroCommerce and the European Retail Round Table, launched the Retailers Environmental Action Plan (REAP). A total of 16 large retailers including, Rewe, Ahold Delhaize, Carrefour, Lidl, Marks and Spencer, Metro, Tesco, and Auchan and 3 retail trade associations, looked to improve the environmental performance of the retail sector of the economy and to engage with the whole of the supply chain. EuroCommerce and the European Retail Round Table (2015b, p.1) suggested that in addressing environmental challenges, retailers 'favour an approach that champions innovation and development where it counts - at company level leading to significant improvement overall when individual companies' results are aggregated.' EuroCommerce and the European Round Table (2015b) argued that retailers favoured such an approach not only because there are variations in the retail marketplace across Europe but also because the retailers' environmental actions are an important element in their competitive positioning within that marketplace.

More specifically, REAP provides a basis that fosters dialogue amongst its members and along their supply chains via the Retail Forum for Sustainability and its retailers' commitments to the Matrix of Environmental Action Points (MAP) and via a more recently adopted Circular Economy Agreement. The Retail Forum for Sustainability serves as a platform, for example, to enable retailers to identify potential areas to reduce their environmental footprint and to share best practice and commitments. Under the MAP retailers committed themselves to a range of environmental actions and initiatives that would contribute to sustainable production and consumption. The MAP commitments look to address the positive environmental impacts the retailers can have on the design and production of the products they sell and on both the distribution and consumption of these products.

In June 2016 the signatories of REAP pledged their commitment to the implementation of a more circular economy. In outlining its commitment to the circular economy, the European Retail Round Table (2016, p.1) recognised its 'increasing responsibility and interest in supporting greater sustainability in both environmental, economic and social terms' and claimed that 'sustainability is at the core of retailers' business models.' More specifically the European Retail Round Table (2016, p.1) argued that 'transitioning to a circular economy will allow us to reduce our dependency on virgin materials and improve our exposure to volatile commodity prices.'

In the light of these general pledges from the European Retail Round Table the authors looked to make a preliminary review of the extent to which Europe's leading retailers had publicly signaled and evidenced their individual commitment to the circular economy. To this end, and given the EuroCommerce and European Retail Round Table (2017) suggestion that environmental challenges are best addressed at the company level, the authors undertook an exploratory search to ascertain if, and how, Europe's 25 leading retailers, as ranked by revenue (Deloitte 2017), cited their commitment to the circular economy on their corporate websites. An Internet search was conducted in November 2017 using each of the leading retailers' names and circular economy as the key words. This search revealed that 12 retailers, namely Carrefour, Metro, Casino, Rewe, Ahold Delhaize, Ikea, LVMH, Migros-Genossenschafts, Inditex, H\&M, Marks and Spencer, and Kingfisher, of the top 25 European retailers publicly and explicitly addressed the circular economy on their corporate websites. A number of illustrative examples and quotations, drawn from the corporate websites, provide an indication of the retailers' general commitment and approach to the concept of the circular economy. All the quotations cited in the following paragraphs in this section of the paper were taken from those corporate websites.

In his Chief Executive Officer's message in the preface to H\&M's 2016 sustainability report, Karl-Johan Persson argued that the transition to a circular economy is essential if the company is to continue to offer sustainable fashion to present and future generations in a world with growing populations and finite resources.' $\mathrm{H} \& \mathrm{M}$ reported its commitment to become ' $100 \%$ circular and renewable', which will involve 'building circularity into every stage of our value chain, including the products we make and the materials we use in our operations.' $H \& M$ also reported on its aspirations to become circular on $80 \%$ of its store concepts by 2025 , using recycled or sustainably sourced materials by 2030 , achieving zero 
discharge of hazardous chemicals in all of the company's production procedures by 2020 and having waste storage and recycling systems at 100\% of its stores by 2020. Marks and Spencer emphasised that 'we support the transition to a sustainable circular economy and will prioritise business model innovation and put circular ways of working into practice.' In 2017 the company relaunched its sustainability Plan A 2025' which included the goal of 'being a circular business generating zero waste' which will include 'designing our products and packaging to underpin the creation of a circular economy in the markets we serve.'

Under the banner, 'Thinking in Circles' Ikea argued 'we always look for ways to make more from less. But to help our customers create a better life at home, in a world where resources are scarce, we have to up our game. We need to rethink everything from the materials we use, to bow we power our stores, and how we can make our products live longer in a cycle of repair, reuse, and recycling. Throughout our value chain, we aim to use renewable and recycled resources as efficiently as possible, to make sure that we create value rather than waste. And when you bring the products home, we want to help you make them live longer, or give them a new life when you no longer need them.' In effectively adopting a life cycle approach, Ikea argued that 'to make the world a more sustainable place we have to begin somewhere. By planning for our products' next life at the design stage, we get a bead start. To make more from less, we also use materials that are renewable and recycled and from more sustainable sources. Our products must last as long as they are needed and be easy to care for, repair, reuse, reassemble, and recycle. The better we do this, the better for our customers and our planet.' In a similar, but much more succinct vein Rewe simply reported that the company practiced 'the principle of a circular flow model.

Kingfisher reported on how it was 'seizing opportunity in a circular economy', and argued that what the company described as 'closed loop products' were at 'the heart of the opportunity.' The company claimed that 'ultimately we want to see a world where creating and using products wastes nothing - and by 2020 we want to have 1,000 products on our shelves with closed loop credentials.' By way of specific illustration of its progress in pursuing a circular economy Kingfisher cited a number of examples. Kingfisher's Castorama chain in France have worked in partnership with Le Relais, a recycling social enterprise, in a scheme which enables customers to dispose of old clothes, and linens in containers outside some of the companies' stores. The textiles are sorted by their condition and quality and $55 \%$ are cleaned and resold, $10 \%$ are turned into cleaning cloths, $25 \%$ are pulped and returned to simple fibres and the remaining $10 \%$ that cannot be recovered are used to generate energy. The newly created fibres are remanufactured to make a range of thermal and acoustic insulation materials that are available in some 38 Castorama stores in France. In a similar vein Kingfisher reported that Screwfix UK was extracting valuable parts, plastics and metals from used and damaged power tools collected in store. These tools are broken down into ten different streams and each stream is sold to specific companies who repurpose the parts or materials.

Inditex headlined a Focus on a Circular Economy' as one of its sustainability priorities. Inditex claimed 'to facilitate our garments having a second life, in 2015 we launched "Closing the Loop." The aim of this initiative is the reuse and recycling of textile products, footwear and accessories, strengthening the circular economy in our sector. At the same time, this promotes social employment and collaboration with social entities and the third sector in our community.' Inditex further reported 'in 2016, we extended this programme to a total of 394 stores in six countries, reaching 100\% implementation in the Zara stores in Spain, Portugal, the United Kingdom, Ireland, Holland and Denmark. This will soon be completed in Sweden and China. In the stores in these countries, we placed specific containers to facilitate donation by our customers. In the same way, we have placed containers in all of our offices and logistic centres in Spain, in order to encourage this initiative among our employees.' Under the banner 'Promoting the Circular Economy', Ahold Delhaize outlined its work in looking for 'innovative solutions to reduce food waste' and in 'continuously looking for ways to create new products from what was once discarded, contributing to the circular economy.'

Carrefour described itself as 'a promoter of the circular economy.' Carrefour reported, for example, that 'the goal is to recycle all waste. This is referred to as the circular economy.' Further Carrefour reported that 'in all the countries where the Group operates, its teams work on developing solutions based on a circular economic model, the aim being to reduce dependency on traditional fuels' and the company described its approach to bio waste management as being 'a unique virtuous loop.'Metro argued that the company was 'devoted to the issue of circular economy' and had introduced 'various goals and measures designed to contribute to achieving a circular economy' including

- Establishing collection points for used cooking fats and oils for reuse as energy sources

- Not providing free plastic bags, in order to reduce the use of resources

- Developing a customer guidance system for products which can be recommended in terms of sustainability in order to support conscious purchase decisions.'

Casino cited 'reducing and reusing waste to promote a circular economy and fight pollution' as one of its corporate social responsibility commitments and evidenced this commitment with specific examples of how the company sorted and recycling store waste within stores in France, Brazil and Colombia. Two companies namely, LVMH and Migros-Genossenschafts were less direct in their corporate commitment to the circular economy. LVMH, for example, reported being a partner in the European Commission's 'Green Week' which was around the theme of 'the Circular Economy' related to 'recycling, re-use and energy recovery'. Migros-Genossenschafts reported supporting the revision of current environmental legislation in Switzerland for more voluntary measures for the green economy including 'careful use of resources and the circular economy.' 


\section{REFLECTIONS}

Overall, 12 of the selected 25 European retailers signalled a commitment to the circular economy and to the principles underpinning it, albeit in varying measure, and a number of them looked to evidence their commitment within their retail operations. This in turn, would suggest that the concept of the circular economy has attracted attention not only from the European Retail Round Table but also at company level within the retail sector of the European economy. That said, a number of more general issues surrounding the concept of the circular economy merit attention and discussion. Firstly, many of the retailers' commitments to the circular economy seem to lack a wholehearted and comprehensive public corporate strategic stamp and often they are evidenced across a limited area of retailers' activities rather than throughout the whole of the retail supply chain and more widely across the product life cycle.

In part, this finding reflects not only the selected retailers seeming reluctance to publicly offer a comprehensive definition of the concept of the circular economy but also to publicly provide any insights into their strategic management of the circular economy. This, in turn, mirrors wider uncertainties about the concept. While the World Economic Forum (2016, webpage) described the circular economy as 'a proven concept', Korhonen et al. (2018, p.37), suggested that the 'circular economy seems to be a collection of vague and separate issues from several fields.' Gregson et al. (2015, p.218) argued the idea of the circular economy is 'more often celebrated than critically interrogated' and that 'its actual enactment is limited and fragile.' At the same time Urbinati et al. (2017, p.487) suggested that academics 'within the strategic management field' are 'struggling with a lack of a framework explaining how companies willing to become circular adapt their existing business model or create new one.'

In part, the lack of a wide-ranging strategic corporate endorsement for the circular economy might also reflect the reality that the leading European retailers are just embarking on a circular economy journey and that they are likely to encounter major operational difficulties along that journey. While they can certainly influence the players within their supply chains they cannot fully control them and they have arguably less influence and control of the often complex and diverse life cycles of the products and services they sell. At the same time, many of the selected retailers' commitments to the circular economy are aspirational. Looking to the future, within what seems likely to be an increasingly competitive multichannel retail marketplace, it remains to be seen how far leading retailers will chose to pursue these aspirations as a contribution of the wider transition to a more sustainable future.

Secondly, the transition to a circular economy within the retail sector of the economy would both drive and demand major changes in consumer behaviour and consumption patterns. At the very least retailers may need to look to give greater focus on providing consumers with clearer information on the environmental impacts of their buying behaviour, in an attempt to reduce household, particularly food, waste, and on more general and sustained educational and public awareness initiatives designed to promote more responsible environmental attitudes to consumption. More fundamentally, the transition to a circular economy within the retail sector of the economy would certainly constitute a dramatic change in the ways in which consumers approach consumption and arguably see the emergence of a 'new consumption culture' (Korhonen et al. 2018, p.41). Indeed the emergence of such a new culture of consumption with 'user groups and communities sharing the use of the function, service and value of physical products (Korhonen et al. 2015, p.41) and where co-operative is perhaps central to the circular economy.

The transition to a circular economy could see the growth of a larger service economy with a greater accent on consumers leasing products as and when they are required, rather than on purchasing and owning products, and then discarding them when their useful or fashionable life was seen to be at an end. Here retailers and brand owners, will need to reframe their relationships with customers, which could, for example, involve digitally monitoring the performance of products and enabling customers to repair products easily. Such a move would surely be seen to challenge the current social value which consumers ascribe to many of the products and services they buy, which may in turn, make it difficult for large numbers of consumers to buy into second hand or reusable patterns of consumption. In some ways this new consumption culture would seem to run counter to the current ethos and business model of the leading retailers. More generally, it thus remains to be seen how enthusiastically consumers will embrace the realities of the circular economy not least because it might be seen by many as a reverse of progress towards a better life that involved 'a sacrifice of our current, tangible needs and desires, in the name of a better but uncertain future' (European Commission 2012, p.9).

Arguably, more critically, there is the thorny, and closely related, issue of sustainable consumption, described by Cohen (2005, p.25) as 'the most obdurate challenge for the sustainable development agenda.' GreenBiz (2015, webpage) argued 'entrenched patterns of overconsumption present a massive burdle to clear before circular economic models can achieve any sort of scale.' In many ways what some commentators see as the continuing and unrestrained pursuit of unsustainable consumption, described by the European Environment Agency (2012) as the 'mother of all environmental issues', might be seen to lie close to the heart of this dilemma. Korhonen et al. (2018, p.8), for example, suggested that 'the most important question for circular economy in terms of long-term sustainable development of global society is how can the saved resources and money generated by the circular economy idea be directed to sustainable consumption practices. If the current consumption culture 
will not change, circular economy will remain as a technical tool that does not change the course of the current unsustainable economic paradigm.'

Thirdly, there are wider, more fundamental and more contentious issues about the relationship between the emergence of a circular economy and existing economic and political structures. Gregson et al. (2015, p.235), for example, argued that a circular economy 'would require radical transformations to the economic order, including fundamental recasting of manufacture, retail, consumption and property rights.' On the one hand, such radical changes would extend far beyond the retail sector of the economy and, given its global supply chains, well beyond Europe. As such, concerns have been expressed that the concept of the circular economy might be captured by corporate interests, and more specifically by corporate capitalism. Valenzuela and Bohm (2017, p.23), for example, suggested that given the all too obvious consequences environmental crises associated with out-of-bounds growth capitalism, the circular economy has been one of the main references for rebuilding and reforming a political economy of sustainable growth.' However, Valenzuela and Bohm (2017, p.27) further argued that the terms circular economy and sustainability were effectively being captured by politiceconomic elites claiming that rapid economic growth can be achieved in a way that manages to remain responsible to environment and society.' In their conclusions Valenzuela and Bohm (2017, p.50) pessimistically suggest that 'the closer we get to the ideal of a fully circular economy, the more we are allowed to consume without taking an ethico-political stance.'

On the other hand there might be seen to be clear parallels here with the ways retailers approached the related concept of sustainable development. Jones et al. (2011), for example, suggested that while many European retailers explicitly stressed their commitment to sustainability they looked, both individually and collectively, to effectively construct their own definitions of the concept. Such definitions 'were built around business efficiency and the search for competitive advantage' and could be seen to be 'driven as much by business imperatives as by a concern for sustainability' (Jones et al. 2011, p.11). In a similar vein, leading European retailers' definitions of the circular economy might be seen to be deliberately vague in that such an approach can pursue a range of business efficiency gains under the circular economy umbrella. More specifically the majority business belief that 'the circular economy would decouple economic growth from resource use' (McKinsey 2015, webpage) can be seen to justify the leading European retailers' commitment to continuing growth, despite wider concerns about the overconsumption of natural resources and the damaging environmental effects of such growth. As such Europe's leading retailers might be seen to be capturing the concept of the circular economy for their own business ends, while effectively and conveniently ignoring the fact that present patterns of consumption may be simply unsustainable in the long term.

\section{CONCLUSION}

The concept of the circular economy has attracted attention from some of leading European retailers and a number of them have publicly addressed how they are introducing the concept within their business operations. Although a number of the leading retailers' initial initiatives have focussed on recycling and zero waste initiatives, a comprehensive approach to the development of a truly circular economy will need to include the whole of the consumer product life cycle embracing product design and production processes, through marketing and consumption as well as waste management. That said at the present time it remains to be seen whether or not the circular economy can become a workable and realistic business model within the retail sector of the European economy. If Europe's leading retailers' public commitments to a more circular economy are to become a reality then they will not only need to effect a radical change in their current business models and that this will need to be accompanied by radical changes in consumers' consumption behaviour. More contentiously, there must be concerns that the leading European retailers might effectively capture the concept of the circular economy to justify continuing economic growth.

This exploratory research note has a number of limitations. Not least in that it draws its information from the material posted on the corporate websites of just 12 leading European retailers and that retail engagement with the concept of the circular economy is in its early stages amongst those retailers. However, the authors believe that their approach is appropriate in what is an exploratory study and that, as such, it provides a platform for future research. Looking to the future, academic research might profitably focus on how specific retailers within Europe are embracing the circular economy and on the challenges and barriers, they face in pursuing such a strategy throughout their supply chains. Further, consumers' perceptions of, and enthusiasms, for the changes the circular economy will demand, will provide valuable insights into what may be a radically changing consumption process. Researchers may wish to explore wider international dimensions of the circular economy. Such enquiries might focus on the extent to which retailers in other parts of the world are embracing the circular economy while and more generally on the ways in which global recycling networks are contributing to the emergence of circular economies. 


\section{REFERENCES}

Accenture Strategy. (2015). Waste to Wealth. Available at: https://www.accenture.com/t00010101T000000Z_w__/gb-en/_acnmedia/Accenture/ConversionAssets/DotCom/Documents/Global/PDF/Strategy_7/Accenture-Waste-Wealth-Exec-SumFINAL.pdf\#zoom=50 (Accessed 8 August 2017)

Cohen, M. J. (2005). Sustainable consumption in national context; an introduction to the symposium. Sustainability, Science Practice and Policy, 1(1), 22-28.

Deloitte. (2017). Global Powers of Retailing. Available at: https://www2.deloitte.com/content/dam/Deloitte/global/Documents/consumer-industrial-products/gxcip-2017-global-powers-of-retailing.pdf_ (Accessed 23 October 2017)

Ellen McArthur Foundation. (2017). Circular Economy Overview. Available at: https://www.ellenmacarthurfoundation.org/circular-economy/overview/concept (Accessed 14 November 2017)

EuroCommerce and the European Retail Round Table. (2015a). REAP 2016-2018: Circular Economy Agreement. Available http:/ /ec.europa.eu/environment/industry/retail/pdf/REAP\%20Circular\%20Economy\%20Agreement.pdf (Accessed 10 November 2017)

EuroCommerce and the European Retail Round Table. (2015b). REAP 2016-2018 Retailers. Environmental Action Programme: Terms of Reference. Available at: http://ec.europa.eu/environment/industry/retail/pdf/reap_tor.pdf (Accessed 11 November 2017)

European Environment Agency. (2012). Unsustainable Consumption-The Mother of All Environmental Issues. Available at: https://www.eea.europa.eu/highlights/unsustainable-consumption-2013-the-mother (Accessed 26 November 2017)

European Retail Round Table. (2016). Circular Economy. Availavble at: http://www.errt.org/sites/default/files/Circular\%20Economy\%20Position\%20Paper.pdf (Accessed 15 November 2017)

European Retail Round Table. (2017). How to Make the Circular Economy Happen - Retailers' Approach. Available at: http://www.errt.org/content/how-make-circular-economy-happen- $\%$ E2\% $\% 0 \% 93$ retailers\%E2\%80\%99-approach (Accessed 13 November 2017)

European Commission. (2012). Policies to Encourage Sustainable Consumption. Available at: http:/ / ec.europa.eu/environment/ eussd/pdf/report_22082012.pdf (Accessed 8 August 2017)

European Commission. (2015). Closing the Loop - A European Union Action Plan for the Circular Economy. Available at: http:// eur-lex.europa.eu/legal-content/EN/TXT/?uri=CELEX\%3A52015DC0614 (Accessed 2 August 2017)

EY. (2015). Are you Ready for the Circular Economy. Available at: http://www.ey.com/Publication/vwLUAssets/EY-brochure-cas-are-you-ready-for-the-circulareconomy/\$FILE/EY-brochure-cas-are-you-ready-for-the-circular-economy.pdf (Accessed 8 August 2017)

GreenBiz. (2015). Defining the Circular Economy. Available at: https://www.greenbiz.com/article/definingcircular-economy-beyond-recycling-material-reuse (Accessed 14 November 2017)

Gregson, N., Crang, M., Fuller, S. and Holmes, H. (2015). Interrogating the Circular Economy: The Moral Economy of Resource Efficiency in the EU. Economy and Society, 42(2), 218-243. https://doi.org/10.1080/03085147.2015.1013353

Jones, P., Comfort, D. and Hillier, D. (2011). Sustainability in the European Shop Window. European Retail Research, 26(1), 1-19.

Korhonen, J., Honkasalo, A. and Seppala, J. (2018). Circular Economy: The Concept and its Limitations. Ecological Economics, 143(1), 37-4. https://doi.org/10.1016/j.ecolecon.2017.06.041

McKinsey and Company. (2015). Europe's Circular-Economy Opportunity. Available at: http://www.mckinsey.com/business-functions/sustainability-and-resource-productivity/ourinsights/europes-circular-economy-opportunity (4 August 2017)

Murray, A., Skene, K. and Haynes, K. (2015). The Circular Economy: An Interdisciplinary Exploration of the Concept and Application in a Global Context', Journal of Business Ethics. Availavble at: http://eprint.ncl.ac.uk/file_store/production/208884/EB16068A-8D6E-4D8F-9FA3-83DF5775D4FE.pdf (Accessed 7 August 2017)

PricewaterhouseCoopers. (2017). Going Circular-Overview. Available at: http://www.pwc.co.uk/who-weare/corporate-sustainability/waste/going-circular/going-circular---overview.html (Accessed 8 August 2017)

Urbinati, A., Chairing, D. and Chiesa, V. (2017). Towards a New Taxonomy of Circular Economy Business Models. Journal of Cleaner Production, 168, 487-498. https://doi.org/10.1016/j.jclepro.2017.09.047 
Valenzuela, F. and Bohm, S. (2017). Against Wasted Politics: A Critique of the Circular Economy. Ephemera: theory and Politics in Organization, 17(1), 23-60.

Wiese, A., Zielke, S and Toporowski, W. (2015). Sustainability in Retailing- Research Streams and Emerging Trends. International Journal of Retail and Distribution Management, 43(4/5), $293-300$. https:/ / doi.org/10.1108/IJRDM-02-2015-0024

World Economic Forum. (2014). Towards the Circular Economy: Accelerating the Scale-Up Across Global Supply Chains. Available

http://www3.weforum.org/docs/WEF_ENV_TowardsCircularEconomy_Report_2014.pdf (Accessed 6 August 2017)

World Economic Forum. (2016). From Linear to Circular- Accelerating a Proven Concept. Available at: http:/ / reports.weforum.org/toward-the-circular-economy-accelerating-the-scale-up-across-global-supplychains/from-linear-to-circular-accelerating-a-proven-concept/ (Accessed 14 November 2017). 